\title{
PKM PELATIHAN KELOMPOK ANAK CINTA LINGKUNGAN KABUPATEN ENDE DALAM PEGELOLAAN LIMBAH ORGANIK DAN ANORGANIK BERBASIS 3R UNTUK MENGESKALASI NILAI EKONOMIS BARANG SEBAGAI BEKAL WIRAUSAHA MANDIRI
}

\author{
Lely Suryani*1, Ariswan Usman Aje ${ }^{2}$, Kristianus J. Tute ${ }^{3}$ \\ 1,2Program studi Pendidikan Matematika, Fakultas Keguruan dan Ilmu Pendidikan \\ Universitas Flores \\ ${ }^{3}$ Program Studi Sistem Informatika, Fakultas Teknologi Informasi Universitas Flores \\ *E-mail : lelypane@gmail.com
}

\begin{abstract}
It is hoped that through these training activities, it could develop the skills of children at the Anak Cinta Lingkungan (ACIL) in Ended in preparing new cadres with independent entrepreneurial spirit and awareness of environmental issues in managing organic and inorganic waste into valuable items economically. The development of skills in this context including: designing, implementation of appropriate technology, management and marketing strategies. Partner of this activity was an organisation of group of children known as ACIL that located $8 \mathrm{~km}$ from University of Flores, at Jalan Aji Sucipto RT 08 / RW 03 Kelurahan Tetandara, Kecamatan Ende Selatan, Kabupaten Ende. The community service carried out for a period of seven (7) months. The activities include; $3 R$ workshops (reuse, reduce and recycle), training on up-cycle household waste to the economically valueable products with appropriate technology, and management training on how to market their handicraft products.
\end{abstract}

Keywords-Organic waste, inorganic, kelompok anak cinta lingkungan, entrepreneur

\begin{abstract}
Abstrak
Dengan diadakannya kegiatan pelatihan ini diharapkan dapat mengembangkan keterampilan anak-anak usia dini kelompok Anak Cinta Lingkungan (ACIL) Kabupaten Ende dalam menyiapkan kader-kader baru yang berjiwa wirausaha mandiri dan mencintai lingkungan hidup dengan cara mengelolah sampah organik dan anorganik menjadi barang bernilai ekonomis. Pengembangan yang dimaksudkan meliputi: desain, implementasi teknologi tepat guna, manajemen dan strategi pemasaran. Mitra dari kegiatan pengabdian ini adalah kelompok ACIL terletak 8 km dari Universitas Flores dan beralamat di Jalan Aji Sucipto RT 08/RW 03 Kelurahan Tetandara. Kegiatan pengabdian masyarakat ini dilaksanakan selama kurun waktu tujuh (7) bulan. Kegiatan yang direncanakan berupa: workshop $3 R$ (reuse, reduse dan recycle), pelatihan pembuatan barang-barang bernilai ekonomis dari limbah rumah tangga dengan teknologi tepat guna, serta pelatihan manajemen bagaimana memasarkan produk hasil kerajinan tangan mereka.
\end{abstract}

Kata Kunci_Limbah organik; anorganik; kelompok anak cinta lingkungan; wirausaha.

\section{PENDAHULUAN}

Bumi adalah rumah kita itu dulu, tapi sekarang rumah kita sudah tidak sehat lagi. Itu karena akhir-akhir ini jumlah limbah sangat meningkat, dan hal ini menyebabkan dampak yang cukup buruk kepada lingkungan. Menurut (Ign Suharto, 2011) limbah adalah bahan atau zat yang sudah tidak digunakan lagi setelah proses kegiatan manusia. Lingkungan mempunyai batas toleransi, apabila limbah sudah melebihi ambang batas toleransinya, maka keseimbangan lingkungan akan terganggu [1]. Hal ini akan berdampak negatif bagi lingkungan dan akan mengganggu kesehatan manusia, hewan dan sekitarnya. Tingkat bahaya limbah itu sendiri tergantung dari jenis limbah tersebut. 
Dalam mencapai kondisi masyarakat yang hidup sehat dan sejahtera dimasa yang akan datang, akan sangat diperlukan adanya lingkungan pemukiman yang sehat. Dari aspek persampahan, maka kata sehat berarti sebagai kondisi yang akan dapat dicapai bila sampah dapat dikelola secara baik sehingga bersih dari lingkungan pemukiman dimana manusia beraktifitas di dalamnya (Maya, Haryono, \& Kholisya, 2018) [2]. Didalam UU No 18 Tahun 2008 tentang pengelolaan sampah, disebutkan sampah adalah sisa kegiatan sehari-hari manusia atau proses alam yang berbentuk padat atau semipadat berupa zat organik atau anorganik bersifat terurai atau tidak dapat terurai yang dianggap sudah tidak berguna lagi dan dibuang kelingkungan (Hadi et al., 2017)[3].

Dewasa ini, sampah menjadi salah satu permasalahan yang cukup sulit ditangani di Indonesia. Hal ini terjadi karena kebiasaan masyarakatnya sebagai konsumen yang selalu menghasilkan sampah (Rizqy Fadhlina \& Rini Fadhillah, 2017) [4]. Oleh karena itu untuk menanggulangi hal diatas, perlu adanya penaggulangan khusus terhadap keberadaan limbah itu sendiri. Salah satunya dengan cara 3R, reuse, reduse, recycle. Untuk mempermudah proses daur ulang dan pemanfaatan ulang, langkah-langkah yang dilakukan adalah pemisahan, penyimpanan, limbah pengiriman atau penjualan. Pengelolaan sampah berbasis masyarakat adalah upaya penanganan sampah yang melibatkan partisipatif aktif dari masyarakat utuk mengelola sampah mulai dari tahap penimbunan, pengumpulan, pengelolaan sampah hingga pemprosesan akhir (Munas Dwiyanto \& Bambang, 2011) [5].

Selama ini hanya sedikit orang saja yang memanfaatkan barang bekas. Padahal, jika kita mau untuk memanfaatkan barang bekas bisa menjadi sumber penghasilan. Karena barang bekas tersebut bisa kita manfaatkan menjadi barang kerajinan tangan yang memiliki nilai ekonomis. Sudah seharusnya untuk menangani limbah ini, kita harus mulai membangun kesadaran masyarakat dari lingkungan yang menghasilkan limbah itu sendiri, yaitu lingkungan rumah tangga. Dengan mengajarkan lingkungan kita bagaimana cara memanfaatkan barang bekas hasil limbah rumah tangga, setidaknya akan dapat mengurangi limbah itu sendiri dan dapat menjadikan mereka orang yang lebih kreatif, inovatif dan berfikir positif tentang memperbaiki lingkungan kita.

Di kabupaten Ende Nusa Tenggara Timur ada sekelompok anak-anak yang peduli terhadap lingkungan yang di kenal dengan ACIL. Kelompok Anak Cinta Lingkungan (ACIL) awalnya adalah Komunitas baru yang independen merupakan kelompok kecil dari pendidikan pelestarian alam dan lingkungan hidup bagi anak-anak di Kabupaten Ende khususnya dan anak-anak Indonesia pada umumnya. Organisasi ACIL mulai dicetuskan idenya pertama pada Hari Sabtu Tanggal 28 November 2013 oleh Senior Pengasuh Komunitas ACIL yang peduli pada lingkungan. Lewat diskusi dan kesepakatan akhirnya Organisasi ACIL ini didirikan pada Hari Rabu Tanggal 04 Desember 2013.

ACIL merupakan tokoh anak-anak yang dijadikan maskot anak cinta lingkungan untuk membangkitkan minat anak-anak belajar tentang lingkungan hidup. ACIL diasosiasikan sebagai anak yang cerdas, riang, proaktif dan selalu ingin tahu. Ia selalu mengajak anak-anak lain untuk memperhatikan dan belajar tentang lingkungan. Dengan cara ini diharapkan anak-anak bisa mendapatkan informasi berkaitan dengan alam dan lingkungan hidup, baik berupa pengetahuan umum maupun pemahaman dasar tentang lingkungan. Yang pasti program ACIL ini juga dapat disebarluaskan untuk tujuan pendidikan dan non komersial. Dan tentunya sangat cocok sebagai komunitas pembelajaran buat anak-anak terutama untuk menanamkan cinta pada lingkungan hidup.

\section{METODE}

Pelaksanaan kegiatan PKM ini dilaksanakan selama 7 (Tujuh) bulan dari bulan Maret sampai September 2019 di Posko ACIL Jalan Aji Sucipto RT 08/RW 03 Kelurahan Tetandara Kecamatan Ende Selatan Kab Ende. Mitra PKM ini adalah Anggota Anak Cinta Lingkungan Kab Ende yang diikuti oleh mahasiswa Pendidikan Matematika Uniflor dan remaja di sekitar kelurahan Tetandara. Kegiatan dilakukan dengan metode sosialisasi dan penyuluhan, demonstrasi dan pelatihan kreasi serta pendampingan. 


\subsection{Sosialisasi dan Penyuluhan}

Sosialisasi program dilaksanakan setelah tahap persiapan selesai yaitu dengan melakukan pertemuan dengan calon peserta yang mengikuti pelatihan dan mensosialisasikan tentang program yang akan di laksanakan. Sosialisasi dan penyuluhan dilakukan di gedung serbaguna milik Bea Cukai Kabupaten Ende yang berada didepan posko ACIL dengan materi sosialisasi dan penyuluhan mengenai lingkungan terutama sampah, cara pengelolaan sampah yang benar serta pemanfaatan limbah organik dan an organik sebagai hasil kerajinan. Mitra diajak untuk bisa lebih perduli terhadap lingkungan serta mampu menjaga lingkungan sejak usia dini.

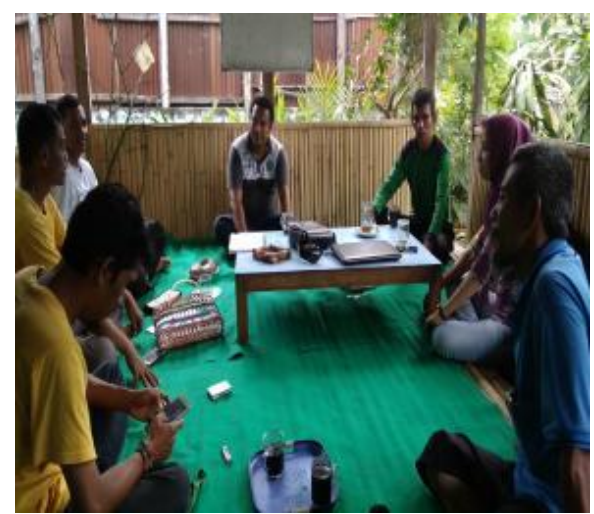

Gambar 1. TIM PKM berdiskusi dengan Mitra
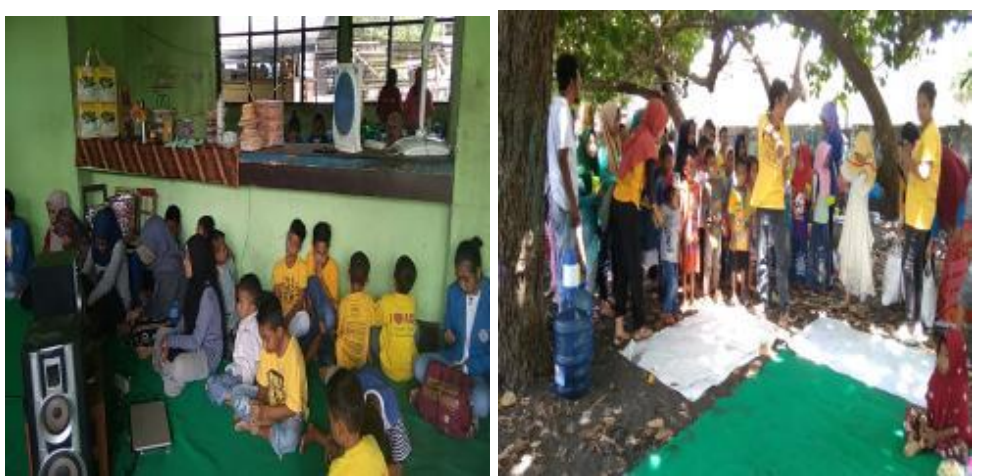

Gambar 2 Sosialisasi dan Penyuluhan

\subsection{Demonstrasi dan Pelatihan Kreasi}

Demonstrasi dan pelatihan kreasi yang diberikan kepada mitra berupa demonstarsi memanfaatkan sisa sampah baik organik maupun anorganik dengan cara 3R, Reuse, reduse dan Recycle. Sampah organik akan diolah menjadi pupuk kompos sedangkan sampah anorganik akan diubah menjadi beberapa hasil kerajinan tangan, seperti tas, piring inkai, tempat lampu, gantungan tanaman, topeng, tas gelang, kompor lapangan, file box dan sebagainya.
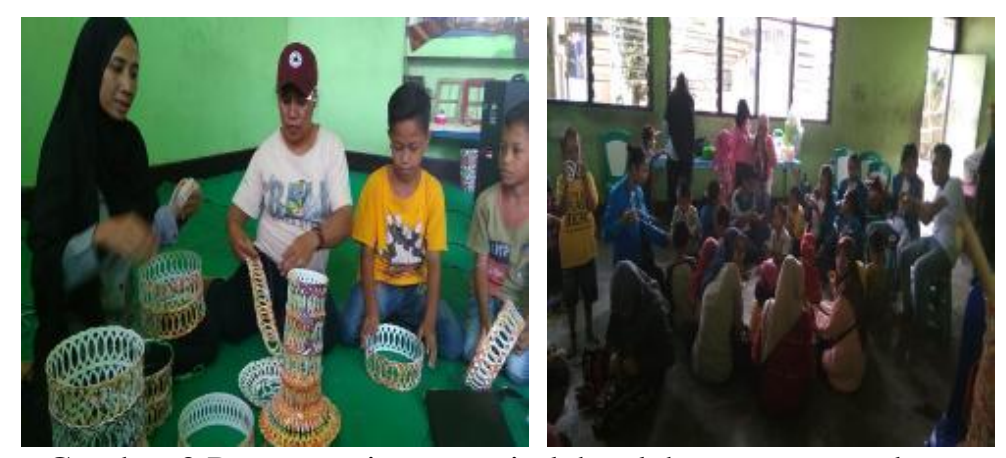

Gambar 3 Penyampaian materi oleh salah satu narasumber 
2.3 Memaksmalkan Fungsi Bank Sampah

Sebenarnya adanya sampah itu akan menjadi peluang usaha, menghasilkan dan menyerap tenaga kerja dengan catatan usaha tersebut dikelola dengan manajemen yang baik. Salah satu model pengelolaan sampah adalah dengan bank sampah (Puji, Dicky, \& Usdek, 2018) [6]. Kelompok ACIL sudahpun memiliki bank sampah, akan tetapi bank sampah ini belum dapat berfungsi maksimal. Oleh karena itu, anggota ACIL diberikan pelatihan manajemen mengenai bank sampah, agar bank sampah dapat dikelola dengan administrasi yang baik sehingga penabung akan percaya pada usaha bank sampah tersebut.

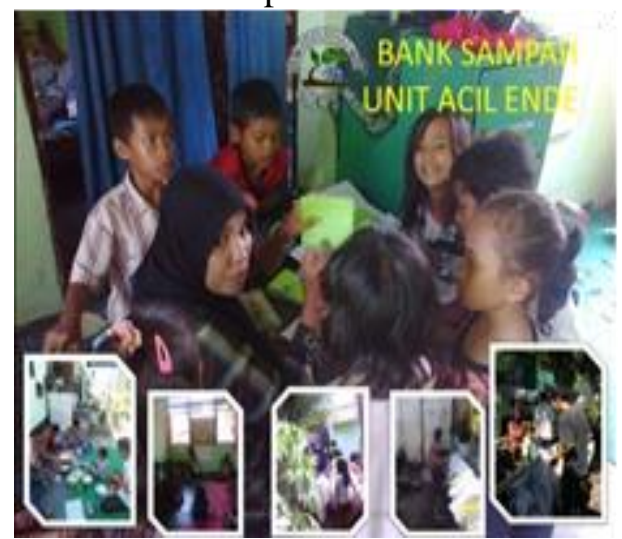

\subsection{Pameran Hasil}

Gambar 4 Bank Sampah Unit Acil Ende

Setelah kegiatan pelatihan kreasi selesai, tim pengabdi dan anggota ACIL melakukan pameran hasil yang dilakukan pada kegiatan Ekspo Kelimutu yang dilaksanakan pada hari Sabtu tanggal 9 Agustus 2019. Pameran hasil ini dilakukan dengan tujuan mengajak masyarakat lebih mencintai lingkungan dengan cara memanfaatkan barang bekas menjadi barang bernilai ekonomis.

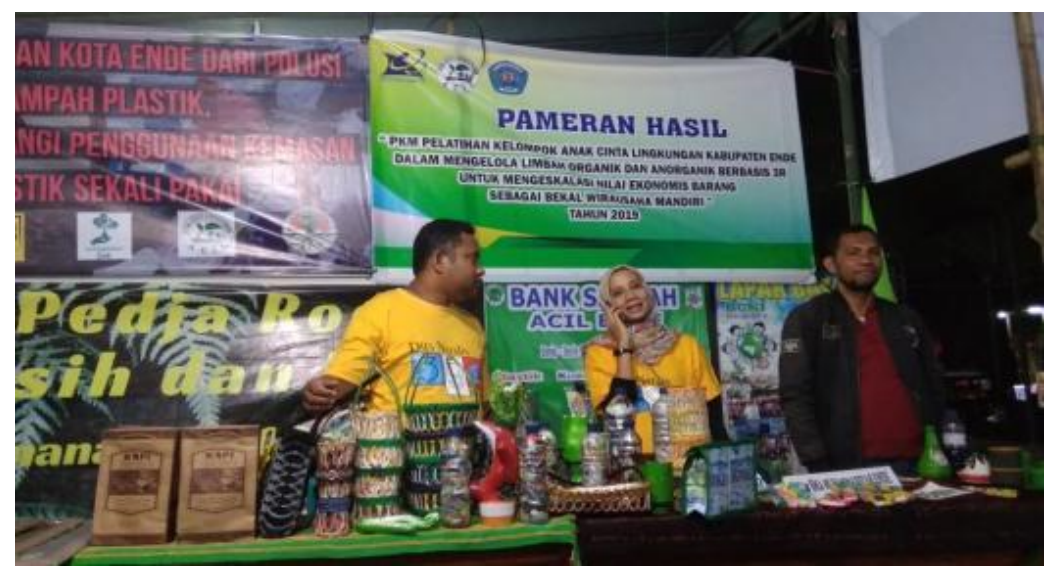

Gambar 5 Pameran Hasil PKM

\subsection{Pendampingan}

Pendampingan dilakukan terhadap kegiatan pembuatan kerajinan tangan, pembuatan pupuk kompos dan kegiatan pemebersihan lingkungan serta cara pemasaran dengan memanfaatkan media sosial. Pendampingan dilakukan dengan cara meninjau langsung kegiatan yang telah dilaksanakan oleh mitra. Ini semua dilakukan agar semua yang telah di sosialisasikan dan di demonstrasikan dapat terlaksana dengan baik dan benar-benar dapat diajadikan sebagai bekal wirausaha mandiri bagi anak-anak sejak usia dini.

\section{HASIL DAN PEMBAHASAN}

Program Kemitran Masyarakat ini dilaksanakan di Posko ACIL Jalan Aji Sucipto RT 08/RW 03 Kelurahan Tetandara Kecamatan Ende Selatan Kab Ende dan juga di lapangan dimana 
mereka melakukan clean up. Pelaksanaan kegiatan PKM ini dimulai dengan melakukan koordinasi dengan mitra. Kemudian Tim Pengabdian dan Mitra yaitu kakak pengasuh/senior ACIL menyusun jadwal yang disepakati dan ditetapkan bersama.

Langkah awal yang dilakukan oleh tim pengabdi untuk melihat sejauh mana kegiatan pengabdian ini berhasil adalah dengan memberikan kuisioner kepada mitra, yaitu kakak Pembina ACIL, pengasuh/senior ACIL dan anggota ACIL mengenai permasalahan lingkungan dan pelatihan kreasi. Kuisioner ini berisi pertanyaan-pertanyaan yang bersifat kualitatif dan kuantitatif. Hasil dari pertanyaan kualitatif diinterpretasikan dalam bentuk deskripsi sedangkan kuantitatif dalam bentuk range angka sehingga dapat diketahui kondisi perubahan yang terjadi sebelum dan setelah pelaksanaan kegiatan pengabdian ini.

Hasil dari bentuk pengabdian masyarakat berupa kegiatan pelatihan kreasi upaya pemanfaatan barang bekas menjadi kerajinan tangan yang bernilai ekonomis sebagai bekal wirausaha mandiri sejak dini. Peserta kegiatan nya adalah Anggota ACIL, mahasiswa Pendidikan Matematika Uniflor dan remaja di sekitar kelurahan Tetandara yang tertarik untuk ikut serta dalam kegiatan pelatihan kreasi ini. Pelaksana kegiatan PKM ini dilakukan oleh 3 (tiga) orang tim pengabdi dengan pokok bahasan yang disampaikan mengenai :

1. Materi Kewirausahaan

2. Pengenalan Pemilahan sampah sejak dini

3. cara pembuangan limbah yang baik dan benar dan 3R (Reuse, Reduce dan Recycle)

4. Bagaimana cara memanfaatkan limbah rumah tangga seperti ale ale, gelas mineral farry, sampah kwaci, kardus, kaleng minuman bekas, Koran, botol air mineral dan sampah sisa tumbuhan sekitar dan sebagainya.

5. Bagaimana cara berkreasi dari bahan sampah hingga menjadi barang bernilai ekonomis Kegiatan PKM dapat berjalan dengan baik karena adanya kerjasama dan koordinasi yang baik dengan mitra. Sosialisasi dan penyuluhan di awal kegiatan dilakukan agar Tim Pengabdi dapat beradaptasi langsung dengan anggota ACIL sehingga dapat mentransfer ilmu pengetahuan dan pelatihan kreasi dengan baik. Kondisi ini memerlukan pemahaman tentang kondisi social budaya masyarakat mitra. Peraturan, norma dan hukum harus dapat dipahami sehingga tim PKM Universitas flores dapat berinteraksi dengan baik (Rosyada A, Warrasih E, \& Herawati R, 2018) [7].

Oleh karena itu, kegiatan pengabdian ini sesuai dengan UU no. 18 tahun 2018 yaitu tentang pengelolaan sampah, paradigma baru pengelolaan sampah memandang sampah sebagai sumber daya yang mempunyai nilai ekonomi dan dapat dimanfaatkan, misalnya, untuk energy, pupuk kompos, ataupun bentuk bahan baku industry. Pengelolaan sampah dilakukan dari hulu kehilir. Salah satu pengelolaan sampah dari hulu kehilir adalah dengan pengurangan sampah, meliputi kegiatan pembatasan (reduce), penggunaan kembali (reuse) dan pendauran ulang (recycle) (Monik Kasman, Hadrah, \& Venny Yusian, 2016) [8].

Apapun pengelolaan sampah baik skala besar maupun skala kecil, bila harus mencapai tujuan nya, yakni lingkungan dan masyarakat yang sehat, maka faktor yang paling utama, yang harus diperhatikan adalah peran serta masyarakat. Hal mengenai proses peningkatan kesadaran masyarakat untuk ikut berpartisipasi dalam hal melestarikan lingkungan hidup dapat dilakukan melalui kegiatan kelompok. Kegiatan ini sebagai media komunikasi untuk merumuskan apa penyebab terjadinya kerusakan lingkungan hidup dan apa pula solusinya (Karim, 2018) [9].

Masyarakat harus mengerti dan mau berpartisipasi bila perlu juga berubah sikap sehingga bersedia membantu mulai dari pengurangan volume sampah, perbaikan kualitas sampah, sampai pada penyediaan lahan, dan pemusnahan sampah (Juli Sumirat Slamet, 1994) [10]. Oleh karena itu diperlukan upaya dan usaha yang terus menerus kepada msayarakat untuk peduli akan lingkungan. Pemberian penghargaan untuk usaha kepedulian juga merupakan salah satu langkah memotivasi masyarakat contohnya program Adiwiyata untuk kepedulian terhadap lingkungan hidup (Kamarullah, Nafsiatun, \& Hendri, 2019)[11]. 


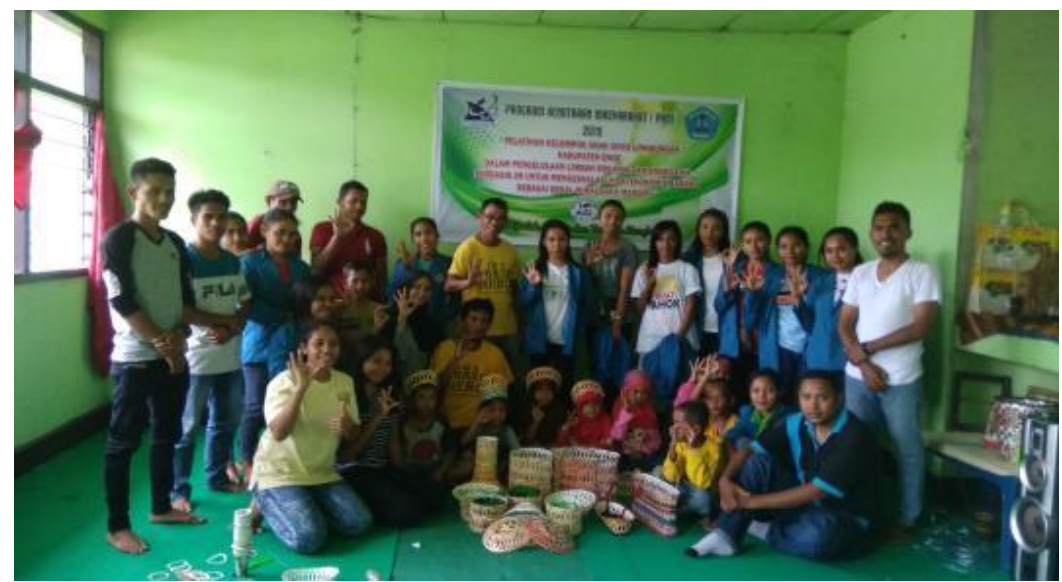

Gambar 6. Tim Dosen PKM dan peserta
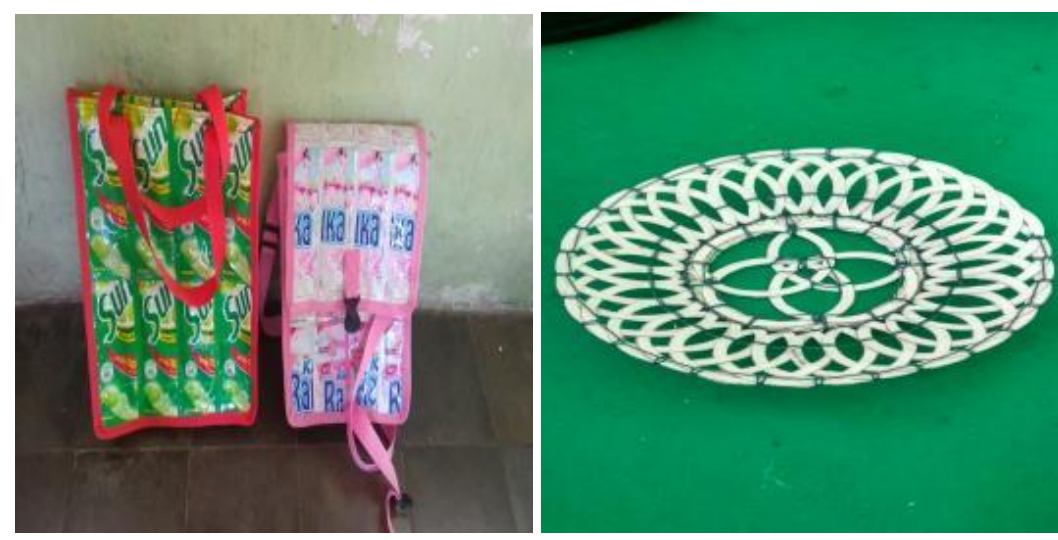

Gambar 7. Hasil Kreasi Tas belanja dan Piring Inkai
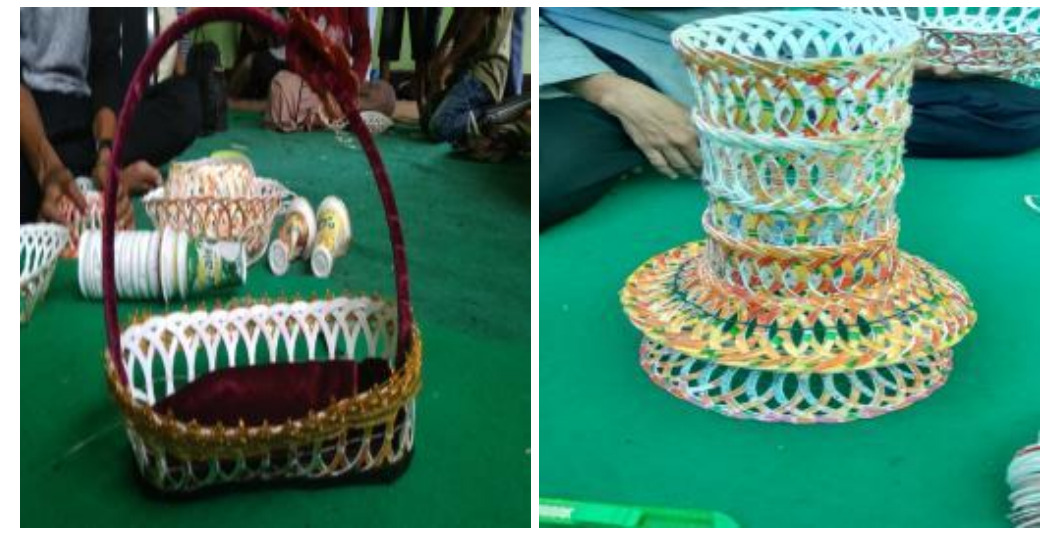

Gambar 8. Hasil Kreasi keranjang dan Bingkai Lampu
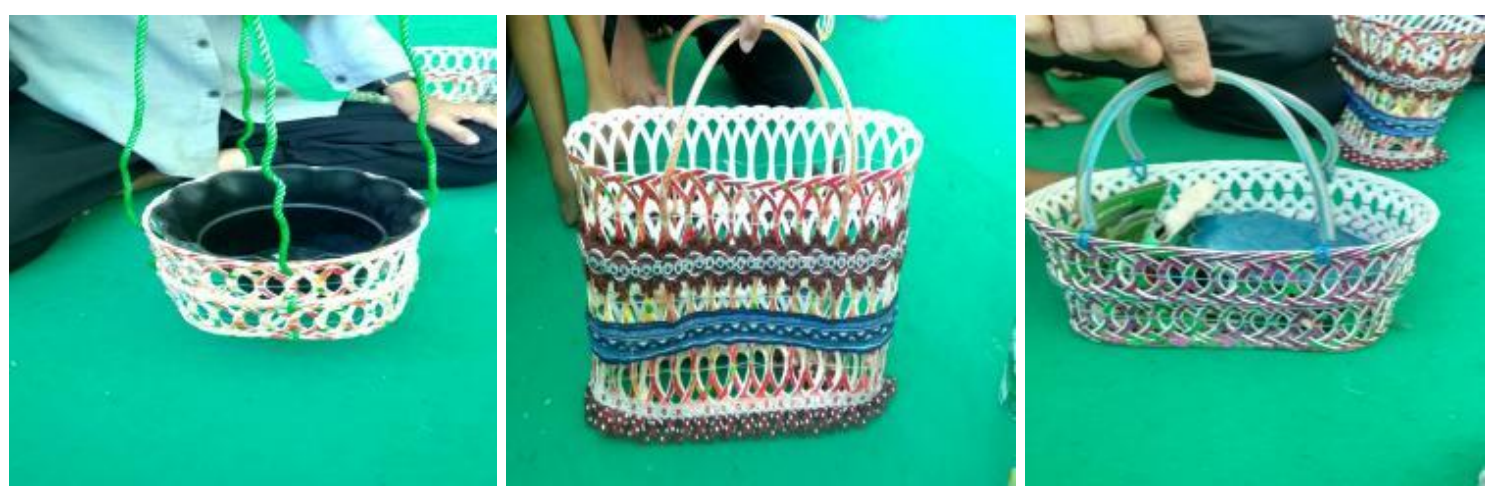

Gambar 9. Hasil Kreasi keranjang tempat bunga, Keranjang Belanja dan Keranjang Buah 

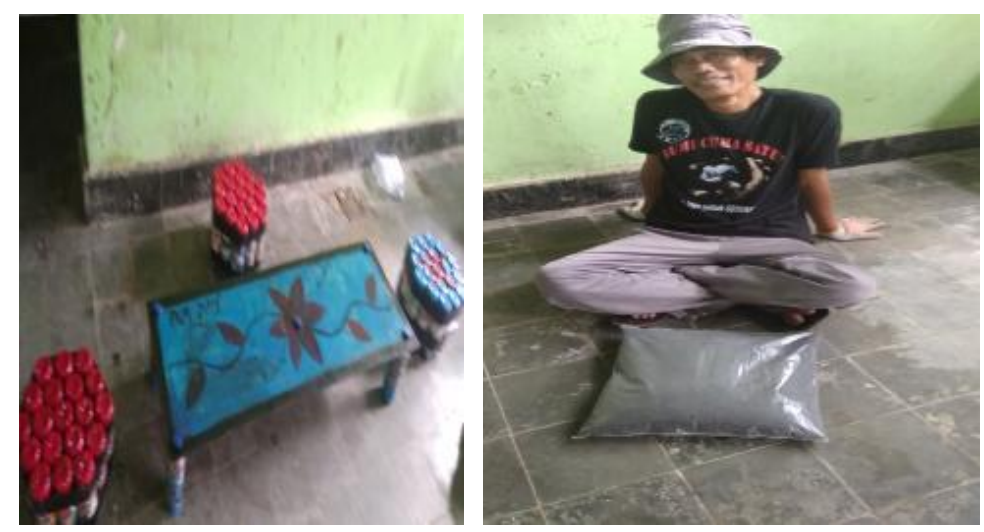

Gambar 10. Ekobrick dan Hasil Pupuk Kompos

\section{KESIMPULAN}

Berdasarkan kegiatan PKM pelatihan kreasi ini bahwa masih banyak barang barang bekas di sekitar kita yang bisa dimanfaatkan sehingga menjadi barang berguna dan bernilai ekonomis. Dengan diadakannya pelatihan kreasi ini:

1. Mitra PKM pelatihan kreasi yaitu anggota ACIL antusias dalam megikuti kegiatan ini selama 7 bulan

2. Mitra PKM pelatihan kreasi yaitu anggota ACIL mengalami peningkatan pengetahuan mengenai Lingkungan dan pemanfaatan sampah dengan cara 3R (reuse, reduse dan recycle) sebesar 30\% yang sebelumnya $60 \%$ menjadi $90 \%$ setelah kegiatan PKM ini.

3. Mitra PKM pelatihan kreasi yaitu anggota ACIL mengalami peningkatan keterampilan dalam hal memanfaatkan barang bekas menjadi kerajinan tangan

4. Mitra PKM pelatihan kreasi yaitu anggota ACIL mengalami peningkatan prilaku cinta lingkungan dengan cara membuang sampah pada tempatnya sesuai dengan jenisnya.

5. Pelatihan ini juga mengajarkan masyarakat dan anggota ACIL bahwa sampah bukanlah sampah tetapi mempunyai nilai ekonomis bila kita bisa memanfaatkanya dengan baik dan maksimal.

6. Kegiatan pelatihan ini juga dapat mengurangi dampak negatif bagi lingkungan sekitar tempat tinggal dan menanamkan kesadaran bagi kita semua bahwa permasalahan sampah adalah tanggung jawab bersama, dimulai dari unsur yang paling kecil yaitu rumah tangga.

\section{SARAN}

Setelah melakukan pengabdian pelatihan kreasi ini, maka ada beberapa saran yang diberikan kepada masyarakat secara luas dan anggota ACIL khususnya yaitu hendaknya menumbuhkan kesadaran terhadap kebersihan lingkungan dengan memanfaatkan barang bekas menjadi barang yang berguna kembali dan bernilai jual dan menanamkan pentingnya berwirausaha sehingga masyarakat dan anggota ACIL dapat menciptakan peluang usaha dengan kreativitasnya melalui pelatihan kreasi membuat kerajinan tangan dari barang bekas yang dapat dimanfaatkan kembali di sekitar lingkungan tempat tinggal.

\section{UCAPAN TERIMA KASIH}

Penulis mengucapkan terima kasih kepada KEMENRISTEKDIKTI yang telah memberi dukungan financial terhadap PKM Pelatihan Kelompok Anak Cinta Lingkungan Kabupaten Ende Dalam Pengelolaan Limbah Organik dan Anorganik Berbasis 3R Untuk Mengeskalasi Nilai Ekonomis Barang Sebagai Bekal Wirausaha Mandiri Universitas Flores Tahun Anggaran 2019. Penulis juga mengucapkan terimakasih kepada mitra yaitu Kelompok Anak Cinta Lingkungan Kabupaten Ende yang telah memberikan kerja sama yang baik sehingga pengabdian ini dapat terlaksana dengan baik. 


\section{DAFTAR PUSTAKA}

[1] Ign Suharto. (2011). Limbah Kimia dalam Pencemaran Air dan Udara. Yogyakarta: CV Andi Offset.

[2] Maya, S., Haryono, S., \& Kholisya, U. (2018). Pemberdayaan Masyarakat Melalui Pengelolaan Sampah Menjadi Nilai Ekonomis dan Pembentukan Bank Sampah di Kelurahan Tanjung Barat. Proceeding of Community Development, 1(2017), 157. https://doi.org/10.30874/comdev.2017.21

[3] Hadi, M. F., Darwin, R., Widiarsih, D., Hidayat, M., Murialti, N., \& Asnawi, M. (2017). Pemanfaatan Barang-Barang Bekas Yang Produktivitas Jiwa Entrepreneur Ibu Rumah. 2(1). Retrieved from http://ejurnal.umri.ac.id/index.php/PengabdianUMRI/article/download/232/140

[4] Rizqy Fadhlina, \& Rini Fadhillah. (2017). Amaliyah: Jurnal Pengabdian Kepada Masyarakat Volume 1 No. 1 Mei 2017. 1(1), 1-8.

[5] Munas Dwiyanto, \& Bambang. (2011). Model Peningkatan Partisipasi Masyarakat dan Penguatan Sinergi dalam Pengelolaan Sampah Perkotaan. Jurnal Ekonomi Pembangunan, Vol 12(2), 239-256.

[6] Puji, N., Dicky, L., \& Usdek, W. (2018). MATAPPA : Jurnal Pengabdian Kepada Masyarakat IbM Bank Sampah Desa Mojorejo Kota Batu. 1, 23-27.

[7] Rosyada A, Warrasih E, \& Herawati R. (2018). Perlindungan Konstitusional terhadap masyarakat Adat dam mewujudkan Keadilan Sosial. Kanun Jurnal Ilmu HUkum, 20(1), 1-22.

[8] Monik Kasman, Hadrah, \& Venny Yusian. (2016). Pemberdayaan Ibu Rumah Tangga Dalam Pemanfaatan SAmpah Domestik DI Desa Kasang Padak Kecamatan Kumpeh Ulu Kabupaten Muaro Jambi. Sumber Daya Akademik Dan Perpustakaan Universitas PAdjajaran, 2-5.

[9] Karim, A. (2018). Mengembangkan Kesadaran Melestarikan Lingkungan Hidup Berbasis Humanisme Pendidikan Agama. Edukasia: Jurnal Penelitian Pendidikan Islam, 12(2), 309. https://doi.org/10.21043/edukasia.v12i2.2780

[10] Juli Sumirat Slamet. (1994). Kesehatan Lingkungan. Bandung: Gadjah Mada University Press.

[11] Kamarullah, Nafsiatun, \& Hendri, M. I. (2019). Peningkatan Perilaku Peduli Hukum dan Lingkungan Melalui Program Kemitraan Masyarakat Peduli Hukum. Jurnal Pengabdian Kepada Masyarakat Dinamisia, 3(1), 1-6. 